\title{
Assessing Social-Ecological System Resilience in Mainland China
}

\author{
Mengmeng $\mathrm{Hu}^{1,2}$, Junmin Zhang ${ }^{1}$, Jinlou Huang'* \\ ${ }^{1}$ College of Sciences, Shihezi University, Shihezi 832003, China \\ ${ }^{2}$ State Key Laboratory of Urban and Regional Ecology, Research Center for Eco-Environmental Sciences, \\ Chinese Academy of Sciences, Beijing, 100085, China
}

Received: 4 May 2017

Accepted: 2 August 2017

\begin{abstract}
Rapid and extensive economic development in China has resulted in a dramatic increase in the consumption of energy and resources with negative ecological effects. This study sought to define the concept of social-ecological systems (SES) resilience to determine whether a given system can effectively withstand these adverse effects per its quantitative level of resilience. The information entropy method and set pair analysis were adopted to determine SES resilience indicators, including the vulnerability and response capacity of social, economic, and ecological subsystems. Thirty-one provincial regions in mainland China were taken as examples and their respective SES resilience levels were empirically measured. The driving mechanisms of resilience were identified based on the correlations of vulnerability and response capacity with resilience. Provinces with higher resilience were identified along the eastern coast of China, whereas provinces with lower resilience were located in the western and central parts of the country. The direction and rate of the factors differed and were uncertain, but a quadratic linear relationship between a driving factor and resilience was clearly identified. The results also confirmed that the set pair analysis method is suitable for SES resilience measurement.
\end{abstract}

Keywords: social-ecological systems, resilience, vulnerability, response capacity, set pair analysis

\section{Introduction}

The global ecosystem has changed dramatically in recent decades as-affected by climate change and intensive anthropogenic activities, and there is an urgent need to establish innovative techniques for sustainable development. Holling (1973) first pioneered the concept of ecological resilience, which is defined as the ability of an ecosystem to maintain its original state despite disturbances [1]. Modern ecological resilience research

*e-mail:jlhuang@rcees.ac.cn has centered around the complex systems of thresholds, breakpoints, and multiplicity of stable states [2-6].

Humans, who are of course an integral part of nature, depend on the ecosystem for survival while continuously impacting the ecosystem. Resilience is the core framework linking social-ecological systems. When its resilience is improved, the system becomes more capable of tolerating disturbances without collapsing, but by simply transitioning to a qualitatively different stage which is dominated by a different set of processes. Understanding SES resilience can help individuals living within the system to anticipate change and prepare for (or even positively influence) the future. 
In recent years, resilience has become a crucial concept in sustainability research and has gradually become mainstream in SES analysis [7-14]. An SES can be divided into three subsystems: social, economic, and ecological. Although each is only a part of the whole, all are credible and testable representations of the corresponding SES [9] in characterizing the interdependence between humans and their environment.

Resilience has four elements: 1) latitude, which is the maximum extent to which a system can change before losing its ability to recover; 2) resistance, or the ease with which changes occur in the system; 3) precariousness, which is the distance away from the "threshold" system; and 4) panarchy, under which the resilience of the system at the local scale is affected by the states of and changes in the system at different scales owing to crossscale interactions [15]. The latitude of the system depends on the comparative measurements and boundaries of resilience. Panarchy represents uncertainty and imbalance, and its impact on resilience is influenced by other factors in the system. To this effect, the applicable measurement factors of resilience include precariousness and resistance.

There have been numerous studies on social or ecological or social-ecological resilience across the globe in recent years. For example, Olsson et al. (2004) studied adaptive co-management for building resilience in Swedish and Canadian SES [16]. Adger et al. (2005) took the 2004 Asian tsunami and storms on small islands as examples to explore social-ecological resilience to coastal disasters [17]. O'Brien et al. (2004) explored the issue of climate vulnerability in Norway, an affluent country that is generally considered to be resilient to the impact of climate change [18]. Hashemi et al. (2017) studied changes that have occurred in the Iranian farming system and their implications for farmers' resilience to climate change [19]. Several of the models and tools that have been used to measure resilience are summarized in Table 1 .

The complex interactions between different systems and spatial and temporal diversifications make the practical measurement of resilience a very challenging endeavor [6]. Owing to a lack of sufficient data or ability to model uncertainties in the results, scientists and managers have generally failed to use suitable guidelines, tools, or models to analyze SES resilience [14, 20]. A feasible and reproducible method to measure SES resilience has yet to be established. Set pair analysis (SPA) as an uncertainty theory can be used to easily and conveniently analyze the connection degree (e.g., identical, divergent, contrary) of a set pair [23-24]. Measurement factors usually have positive or negative, fast or slow, or linear or non-linear effects on SES functions. In this study, we set out to exploit the advantages of the the SPA model for assessing SES resilience.

System precariousness is mainly via certain vulnerability factors affected by external interference and internal succession. The relationship between resilience and vulnerability is highly complex. This relationship may or may not be negative; it is not a black-or-white description and cannot be simplified as having endpoints on a continuum; thus, the direct link between resilience and vulnerability should be emphasized [25-26]. SES vulnerability is characterized by urban development and varies across different types, characteristics, development modes, and regional environments of urban systems. System resistance is measured mainly through response capacity; differences in the overall levels of SES development, policies, and subsystems result in considerable differences in the response capacity of the system. Building resilience to precariousness with strong resistance is necessary for navigating the SES.

Table 1. Models for measuring SES resilience.

\begin{tabular}{|c|c|c|}
\hline Author (year) & Models (tools) & Contents \\
\hline $\begin{array}{l}\text { Kelly et al. } \\
\text { (2015) }\end{array}$ & $\begin{array}{l}\text { Interviews and collected statistical } \\
\text { data }\end{array}$ & $\begin{array}{l}\text { How economic, social, institutional, political, cultural, and natural factors } \\
\text { affect the decision-making process and ability of communities to adapt and } \\
\text { continually improve their resilience [10] }\end{array}$ \\
\hline $\begin{array}{l}\text { Li et al. } \\
(2014)\end{array}$ & $\begin{array}{l}\text { 1. Indicator-based system } \\
\text { 2. Multi-criteria evaluation method } \\
\text { 3. Spatial visualization based on } \\
\text { GIS }\end{array}$ & $\begin{array}{l}\text { Integrated spatial zonings of different degrees with indicators of ecological } \\
\text { sensitivity, water quality, and vegetation cover are assessed to determine the } \\
\text { practical application of spatial resilience [11] }\end{array}$ \\
\hline $\begin{array}{l}\text { Kotzee } \\
\text { and Reyers } \\
\quad(2016)\end{array}$ & Principal component analysis & $\begin{array}{l}\text { Integrating } 24 \text { resilience indicators and relevant social, ecological, and } \\
\text { economic components to measure resilience to flood disasters [13] }\end{array}$ \\
\hline $\begin{array}{l}\text { Perz et al. } \\
\quad(2013)\end{array}$ & $\begin{array}{l}\text { 1. Uncertainty analysis and } \\
\text { comparing models of varying } \\
\text { complexity } \\
\text { 2. Ball-and-cup diagrams }\end{array}$ & $\begin{array}{l}\text { Applications of these methods to assess of ecosystem management options in } \\
\text { terms of their ramifications for ecological resilience [20] }\end{array}$ \\
\hline $\begin{array}{c}\text { Cutter et al. } \\
\text { (2008) }\end{array}$ & $\begin{array}{l}\text { Disaster resilience of place (DROP) } \\
\text { model }\end{array}$ & $\begin{array}{l}\text { Providing a new framework characterized by a place-based model for } \\
\text { understanding community resilience to natural disasters [21] }\end{array}$ \\
\hline $\begin{array}{l}\text { Zaucha et al. } \\
\text { (2016) }\end{array}$ & Ecosystem services & $\begin{array}{l}\text { Analyzing the possibility of using marine ecosystem services to fuel public } \\
\text { debate on the evolutionary resilience of land-sea interface regions [22] }\end{array}$ \\
\hline
\end{tabular}


This study has three primary objectives:

1) Establish a theoretical model for assessing SES resilience.

2) Understand the correlations of vulnerability and response capacity with resilience.

3) Analyze SES development in 31 provincial regions across mainland China.

In this study, we examined several properties of resilience in the face of economic development interference with vulnerability and response capacity as indicators. An SES resilience measurement framework based on the vulnerability and response capacity of the system was established, and the influencing factors and mechanisms of resilience (as well as the capacity for sustainable development itself) are revealed using the proposed framework.

\section{Materials and Methods}

\section{Study Area}

The study area encompasses 31 provinces in mainland China, excluding Hong Kong, Macao, and Taiwan (Fig. 1). The differences in the social-ecological developments and geographies among these provinces are substantial [2728]. For example, Tianjin had the largest per capita GDP, which was four times higher than that of Gansu in 2014. SESs in China are complex because of the high degree of coupling between nature and society and the relative sensitivity of productive activities. These disparities lead to some interesting questions: Do the SESs of different provinces have sufficient resilience? What factors affect their resilience? How do these factors affect the nature and rate of resilience?

\section{Framework for SES Resilience Measurement}

SES should be examined from a complex perspective accounting for social, economic, and ecological factors, as well as linear or nonlinear feedback and interactions [29-30]. The core of SES factor measurement consists of social stability, economic diversification and growth, ecological and natural factors, and anthropogenic impact. The social subsystem, economic subsystem, and ecological subsystem were selected as the measurement units in this study accordingly. For each subsystem, the vulnerability index and response capacity index were calculated, and the quantitative factors for the object of study were selected.

Combined with literature investigation [31-33], the owned limited data, and the characteristics of the study field, the evaluation index for SES resilience was established and is shown in Table 2. The data was collected mainly from the China Statistical Yearbook (2015).

\section{Set Pair Analysis}

Set pair analysis (SPA), which was first proposed by Zhao (1989) [34], is a comprehensive technique to demonstrate the links between different objects that can be used to study the certainty and uncertainty of the objects. This method is often employed in natural science, social, and economic research [35-38]. A problem always has a degree of uncertainty, including identical degree, discrepancy degree, and contrary degree under certain circumstances [39].

The core idea of SAP is to use certainty and uncertainty as a system. Two sets $A$ and $B$ with some kind of connection are regarded as a set pair $H$. To address a specific problem, the identical/discrepancy/contrary

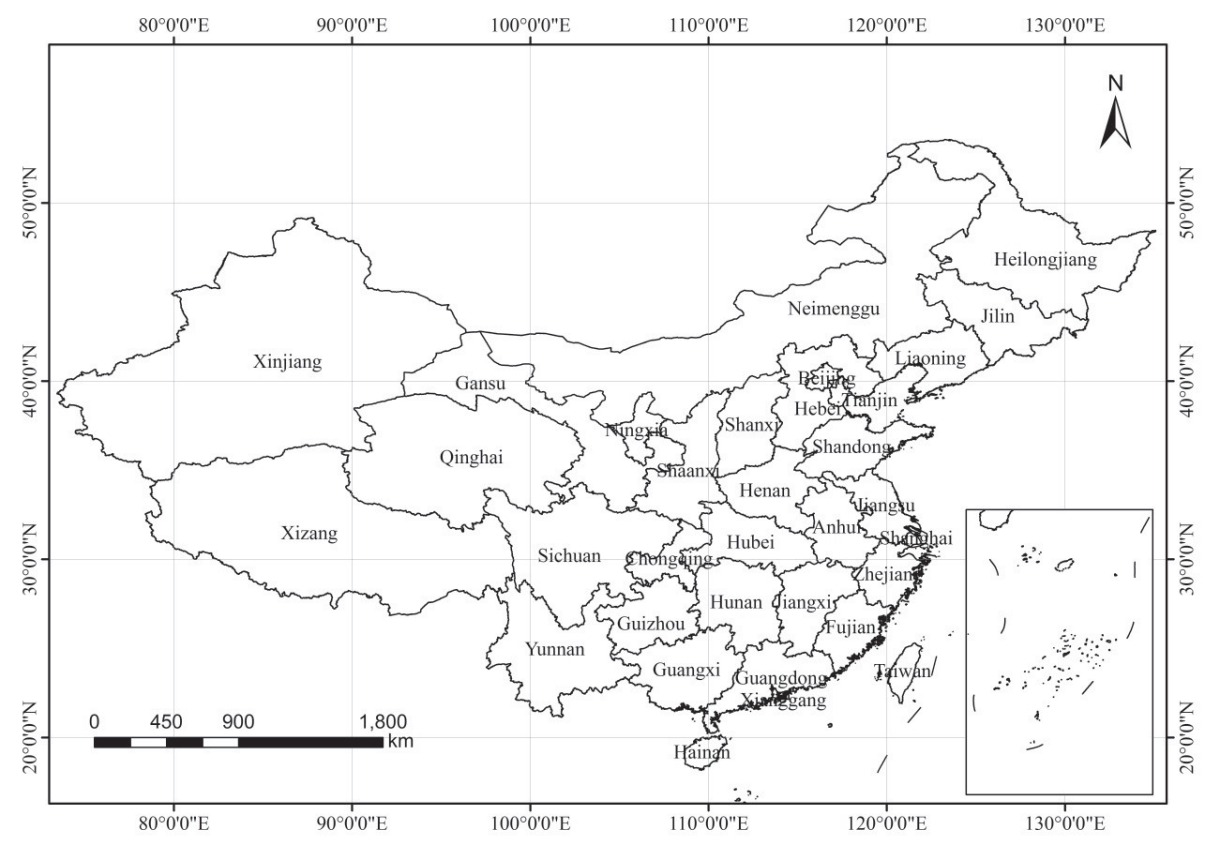

Fig. 1. Chinese provinces in the study area. 
Table 2. SES resilience evaluation index.

\begin{tabular}{|c|c|c|c|c|c|}
\hline Object layer & Project layer & Index layer & Unit & Impact & Weight \\
\hline \multirow{12}{*}{$\begin{array}{l}\text { Social system } \\
\text { resilience } \\
\text { index }\end{array}$} & \multirow{8}{*}{ Vulnerability index } & A1: total population & $10^{4} \mathrm{p}$ & - & 0.0441 \\
\hline & & A2: urbanization rate & $\%$ & + & 0.0383 \\
\hline & & A3: unemployment rate & $\%$ & - & 0.0543 \\
\hline & & A4: number of traffic accidents & Times & - & 0.1330 \\
\hline & & A5: illiterate population & $\mathrm{p}$ & - & 0.0406 \\
\hline & & A6: number of computer users per 100 people & $\mathrm{p}$ & + & 0.1128 \\
\hline & & A7: area of urban green space & ha & + & 0.1502 \\
\hline & & A8: road length & $\mathrm{km}$ & + & 0.1315 \\
\hline & \multirow{4}{*}{ Response capacity } & B1: local fiscal expenditure & $10^{8} \mathrm{RMB}$ & + & 0.0748 \\
\hline & & B2: social security and employment expenditure & $10^{8} \mathrm{RMB}$ & + & 0.0655 \\
\hline & & $\begin{array}{l}\text { B3: number of beds in health care institutions per } \\
\qquad 1,000 \text { people }\end{array}$ & Bed & + & 0.0704 \\
\hline & & B4: education expenditure & $10^{8} \mathrm{RMB}$ & + & 0.0845 \\
\hline \multirow{12}{*}{$\begin{array}{l}\text { Economic } \\
\text { system } \\
\text { resilience } \\
\text { index }\end{array}$} & \multirow{8}{*}{ Vulnerability index } & $\mathrm{C} 1$ : industrial output & $10^{8} \mathrm{RMB}$ & + & 0.0692 \\
\hline & & $\begin{array}{c}\text { C2: proportion of GDP generated by the service } \\
\text { industry }\end{array}$ & $\%$ & + & 0.0859 \\
\hline & & C3: proportion of GDP generated by the industry & $\%$ & - & 0.0827 \\
\hline & & C4: total import and export of goods & $10^{4}$ Dollar & + & 0.2007 \\
\hline & & C5: tax revenue & $10^{8} \mathrm{RMB}$ & + & 0.0744 \\
\hline & & C6: investment in fixed assets & $10^{8} \mathrm{RMB}$ & + & 0.0544 \\
\hline & & C7: deposits of household savings & $10^{8} \mathrm{RMB}$ & + & 0.0632 \\
\hline & & C8: per capita consumption expenditure & RMB & + & 0.0588 \\
\hline & \multirow{4}{*}{ Response capacity } & D1: total financial revenue & $10^{8} \mathrm{RMB}$ & + & 0.0642 \\
\hline & & D2: per capita disposable income & RMB & + & 0.0706 \\
\hline & & D3: per capita GDP & RMB & + & 0.0862 \\
\hline & & D4: average annual income per capita & RMB & + & 0.0897 \\
\hline \multirow{12}{*}{$\begin{array}{l}\text { Ecological } \\
\text { system } \\
\text { resilience } \\
\text { index }\end{array}$} & \multirow{8}{*}{ Vulnerability index } & E1: population density & $\mathrm{P} / \mathrm{km}^{2}$ & - & 0.0516 \\
\hline & & E2: forest cover rate & $\%$ & + & 0.0942 \\
\hline & & E3: area of agricultural land & $10^{4}$ ha & + & 0.1761 \\
\hline & & E4: amount of industrial solid waste & $10^{4} \mathrm{t}$ & - & 0.0260 \\
\hline & & E5: sulfur dioxide emissions & $10^{4} \mathrm{t}$ & - & 0.0420 \\
\hline & & E6: nitrogen oxide emissions & $10^{4} \mathrm{t}$ & - & 0.0530 \\
\hline & & E7: smoke and dust discharge & $10^{4} \mathrm{t}$ & - & 0.0317 \\
\hline & & E8: domestic water-consumption per capita & $\mathrm{m}^{3}$ & - & 0.0267 \\
\hline & \multirow{4}{*}{ Response capacity } & F1: amount of daily sewage treatment & $10^{4} \mathrm{~m}^{3}$ & + & 0.1336 \\
\hline & & F2: area of soil erosion control & 1,000 ha & + & 0.1282 \\
\hline & & F3: amount of industrial solid waste disposal & $10^{4} \mathrm{t}$ & + & 0.1174 \\
\hline & & F4: area of afforestation & ha & + & 0.1195 \\
\hline
\end{tabular}




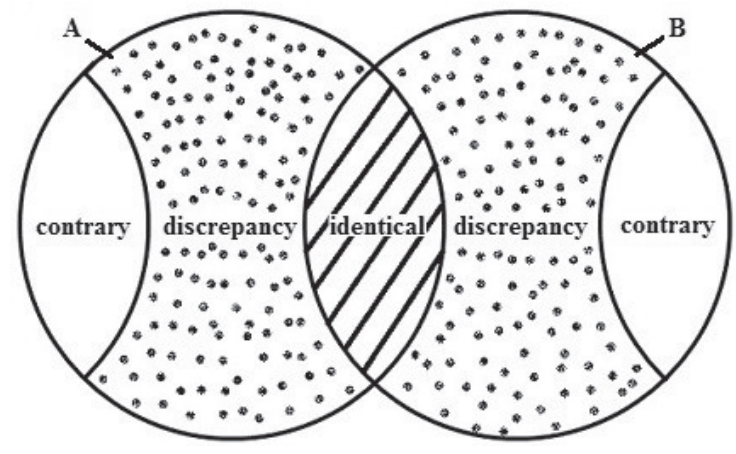

Fig. 2. Degree of connection between two sets.

degree of the two sets are analyzed; according to the needs of question $Q$, the set pair $H$ is composed of sets $A$ and $B$ with $N$ characteristics to be obtained. Among them, $S$ characteristics are identical to two sets, and the two sets are contrary to the other $P$ characteristics. They are neither identical nor contrary but instead have discrepancy in the remaining $F=N-S-P$ characteristics.

The degree of connection $u$ between set $A$ and set $B$ under the specific problem $Q$ can be expressed as follows:

$$
u(Q)=\frac{S}{N}+\frac{F}{N} i+\frac{P}{N} j
$$

...where $u$ is the connection degree of the set pair. Given $a=S / N, b=F / N, c=P / N$, Eq. (1) can be rewritten as follows:

$$
u=a+b i+c j
$$

...where $i$ is the discrepancy degree coefficient satisfying the condition $(i \in[-1,1])$; and $j$ is the coefficient of the contrary degree which is specified as $-1 ; a, b$, and $c$ are the identical degree, discrepancy degree, and contrary degree of sets $A$ and $B$ under problem $T$, respectively, and are satisfied $a+b+c=1$. A diagram of the degree of connection between the two sets is shown in Fig. 2 .

To evaluate a multi-attribute object, the problem space $Q$ based on SPA can be defined as $Q=\{S, M, H, W\}$, where $S$ is the collection of evaluation programs (i.e., $\left.S=\left\{s_{k}\right\}(k=1,2, \ldots, p)\right), M$ is the collection of evaluation indices (i.e., $\left.M=\left\{m_{r}\right\} \quad(r=1,2, \ldots, n)\right), H$ represents the decision-making matrix for problem $Q$ based on SPA (i.e., $H=\left(h_{r}\right)_{p \times n}$ ), and $W$ is the collection of the evaluation index weights (i.e., $W=\left\{w_{1}, w_{2}, \ldots, w_{n}\right\}$ ). A comparative evaluation of programs in the same space can be conducted to determine the best evaluation index, which is denoted by $U=\left\{u_{1}, u_{2}, \ldots, u_{n}\right\}$, and the worst evaluation index, which is denoted by $V=\left\{v_{1}, v_{2}, \ldots, v_{n}\right\}$. The identical degree and contrary degree can be calculated as follows in the comparative interval of $[U, V]$ :

$$
\left\{\begin{array}{c}
u\left(s_{k}\right)=a_{k}+b_{k} i+c_{k} j \\
a_{k}=\sum w_{r} a_{k r} \\
c_{k}=\sum w_{r} c_{k r}
\end{array}\right.
$$

...where $a_{k r}$ is the identical degree, $c_{k r}$ is the contrary degree, and $w_{r}$ is the $r$ th index weight. When $d_{k r}$ has a positive effect on the results of the evaluation, then:

$$
\left\{\begin{array}{c}
a_{k r}=\frac{d_{k r}}{u_{r}+v_{r}} \\
c_{k r}=\frac{u_{r} v_{r}}{d_{k r}\left(u_{r}+v_{r}\right)}
\end{array}\right.
$$

When $d_{k r}$ has a negative effect on the results of the evaluation, then:

$$
\left\{\begin{array}{c}
a_{k r}=\frac{u_{r} v_{r}}{d_{k r}\left(u_{r}+v_{r}\right)} \\
c_{k r}=\frac{d_{k r}}{u_{r}+v_{r}}
\end{array}\right.
$$

Consequently, the approximate degree betweenand $s_{k}$ and $U\left(r_{k}\right)$ can be expressed by the following equation:

$$
r_{k}=\frac{a_{k}}{a_{k}+c_{k}}
$$

The larger the value, the closer the evaluation object is to the optimal solution.

Information entropy was first applied to determine the weight of SPA; the data on impact indicators were standardized to avoid any error induced by subjective factors [40]. The following equation was used:

$$
\begin{gathered}
W_{r}=\frac{\left(1+\frac{1}{\ln p} \sum_{k=1}^{p} \frac{q_{k r}}{q_{r}} \ln \frac{q_{k r}}{q_{r}}\right)}{\left(n+\frac{1}{\ln p} \sum_{r=1}^{n} \sum_{k=1}^{p} \frac{q_{k r}}{q_{r}} \ln \frac{q_{k r}}{q_{r}}\right)} \\
q_{r}=\sum_{k=1}^{p} q_{k r}
\end{gathered}
$$

When index $d_{k r}$ has a positive effect on the results of the evaluation, then:

$$
q_{k r}=\left(h_{k r}-\min \left\{h_{r}\right\}\right) /\left(\max \left\{h_{r}\right\}-\min \left\{h_{r}\right\}\right)
$$

When index has a negative effect on the results of the evaluation, then:

$$
q_{k r}=\left(\max \left\{h_{r}\right\}-h_{k r}\right)\left(\max \left\{h_{r}\right\}-\min \left\{h_{r}\right\}\right)
$$

...where $w_{r}$ denotes the weight of the index $m_{r}, q_{r}$ is the integrated value of the indicator $m_{r}$ for interval set $s$, and $q_{k r}$ is the standardized value calculated from the raw data of indicator $m_{r}$ for interval $\mathrm{s}_{k}$. 
Table 3. Approach degrees of different SES evaluation indexes.

\begin{tabular}{|c|c|c|c|c|c|c|c|c|c|}
\hline \multirow{2}{*}{ Region } & \multicolumn{3}{|c|}{ Vulnerability index } & \multicolumn{3}{|c|}{ Response capacity index } & \multicolumn{3}{|c|}{ SES resilience index } \\
\hline & $a_{k}$ & $c_{k}$ & $r_{k}$ & $a_{k}$ & $c_{k}$ & $r_{k}$ & $a_{k}$ & $c_{k}$ & $r_{k}$ \\
\hline Beijing & 0.7535 & 0.2511 & 0.7500 & 0.3996 & 0.1493 & 0.7279 & 1.1531 & 0.4005 & 0.7422 \\
\hline Tianjin & 0.4170 & 0.4507 & 0.4806 & 0.2893 & 0.2692 & 0.5180 & 0.7063 & 0.7199 & 0.4952 \\
\hline Hebei & 0.4408 & 0.5401 & 0.4494 & 0.5045 & 0.2250 & 0.6916 & 0.9452 & 0.7650 & 0.5527 \\
\hline Shanxi & 0.3490 & 0.5273 & 0.3982 & 0.4529 & 0.2444 & 0.6495 & 0.8019 & 0.7717 & 0.5096 \\
\hline Neimenggu & 0.5515 & 0.4696 & 0.5401 & 0.5797 & 0.1987 & 0.7447 & 1.1312 & 0.6684 & 0.6286 \\
\hline Liaoning & 0.5302 & 0.4337 & 0.5501 & 0.5068 & 0.1837 & 0.7340 & 1.0370 & 0.6174 & 0.6268 \\
\hline Jilin & 0.3993 & 0.4160 & 0.4898 & 0.2738 & 0.2404 & 0.5325 & 0.6732 & 0.6565 & 0.5063 \\
\hline Heilongjiang & 0.4767 & 0.4127 & 0.5360 & 0.3425 & 0.2355 & 0.5926 & 0.8192 & 0.6482 & 0.5583 \\
\hline Shanghai & 0.6198 & 0.4801 & 0.5635 & 0.4296 & 0.1471 & 0.7449 & 1.0494 & 0.6272 & 0.6259 \\
\hline Jiangsu & 0.8019 & 0.4943 & 0.6186 & 0.5923 & 0.1587 & 0.7887 & 1.3941 & 0.6530 & 0.6810 \\
\hline Zhejiang & 0.6493 & 0.4418 & 0.5951 & 0.4340 & 0.1683 & 0.7205 & 1.0833 & 0.6102 & 0.6397 \\
\hline Anhui & 0.4035 & 0.5248 & 0.4347 & 0.3838 & 0.2324 & 0.6229 & 0.7873 & 0.7572 & 0.5098 \\
\hline Fujian & 0.4690 & 0.4227 & 0.5260 & 0.3232 & 0.2112 & 0.6049 & 0.7923 & 0.6339 & 0.5555 \\
\hline Jiangxi & 0.4003 & 0.4663 & 0.4619 & 0.3410 & 0.2443 & 0.5826 & 0.7413 & 0.7106 & 0.5106 \\
\hline Shandong & 0.7022 & 0.5677 & 0.5530 & 0.6021 & 0.1753 & 0.7745 & 1.3043 & 0.7430 & 0.6371 \\
\hline Henan & 0.4239 & 0.5755 & 0.4241 & 0.4792 & 0.2227 & 0.6828 & 0.9031 & 0.7982 & 0.5308 \\
\hline Hubei & 0.4673 & 0.4286 & 0.5216 & 0.4488 & 0.2002 & 0.6915 & 0.9160 & 0.6288 & 0.5930 \\
\hline Hunan & 0.4221 & 0.4694 & 0.4734 & 0.4307 & 0.2133 & 0.6688 & 0.8528 & 0.6827 & 0.5554 \\
\hline Guangdong & 1.0213 & 0.5074 & 0.6681 & 0.6076 & 0.1721 & 0.7793 & 1.6289 & 0.6795 & 0.7056 \\
\hline Guangxi & 0.4289 & 0.4180 & 0.5065 & 0.3191 & 0.2552 & 0.5556 & 0.7480 & 0.6732 & 0.5263 \\
\hline Hainan & 0.4926 & 0.4038 & 0.5496 & 0.1449 & 0.4907 & 0.2280 & 0.6376 & 0.8945 & 0.4161 \\
\hline Chongqing & 0.4035 & 0.3920 & 0.5072 & 0.3245 & 0.2166 & 0.5997 & 0.7280 & 0.6086 & 0.5446 \\
\hline Sichuan & 0.5028 & 0.4966 & 0.5031 & 0.4763 & 0.2055 & 0.6985 & 0.9791 & 0.7021 & 0.5824 \\
\hline Guizhou & 0.3807 & 0.4642 & 0.4506 & 0.3532 & 0.2702 & 0.5665 & 0.7339 & 0.7345 & 0.4998 \\
\hline Yunnan & 0.4271 & 0.4487 & 0.4877 & 0.4366 & 0.2564 & 0.6300 & 0.8637 & 0.7051 & 0.5506 \\
\hline Xizang & 0.7263 & 0.9937 & 0.4223 & 0.1448 & 0.7204 & 0.1674 & 0.8711 & 1.7140 & 0.3370 \\
\hline Shaanxi & 0.3866 & 0.4779 & 0.4472 & 0.4263 & 0.2153 & 0.6644 & 0.8129 & 0.6932 & 0.5397 \\
\hline Gansu & 0.3148 & 0.5057 & 0.3836 & 0.3155 & 0.2984 & 0.5139 & 0.6303 & 0.8042 & 0.4394 \\
\hline Qinghai & 0.4002 & 0.8496 & 0.3202 & 0.2290 & 0.3805 & 0.3757 & 0.6291 & 1.2301 & 0.3384 \\
\hline Ningxia & 0.3374 & 0.5382 & 0.3854 & 0.1994 & 0.3999 & 0.3328 & 0.5369 & 0.9380 & 0.3640 \\
\hline Xinjiang & 0.4063 & 0.5247 & 0.4364 & 0.2872 & 0.2383 & 0.5466 & 0.6935 & 0.7630 & 0.4762 \\
\hline
\end{tabular}

\section{Results and Discussion}

\section{Approach Degrees}

The established framework and SPA were used to calculate the vulnerability, response capacity index, and resilience index of SES. The worst aggregate $V$ and optimal aggregate $U$ need to be selected first as SES indicators. Next, the weights of the indicator system used to evaluate SES resilience (Table 1) can be calculated with Eqs. (7-10). The approach degrees of different SES evaluation indexes (Table 3) can be obtained via Eqs. (4$6)$.

\section{Analysis of Vulnerability}

We used SPA to calculate the vulnerability index, response capacity index, and resilience index of the three 


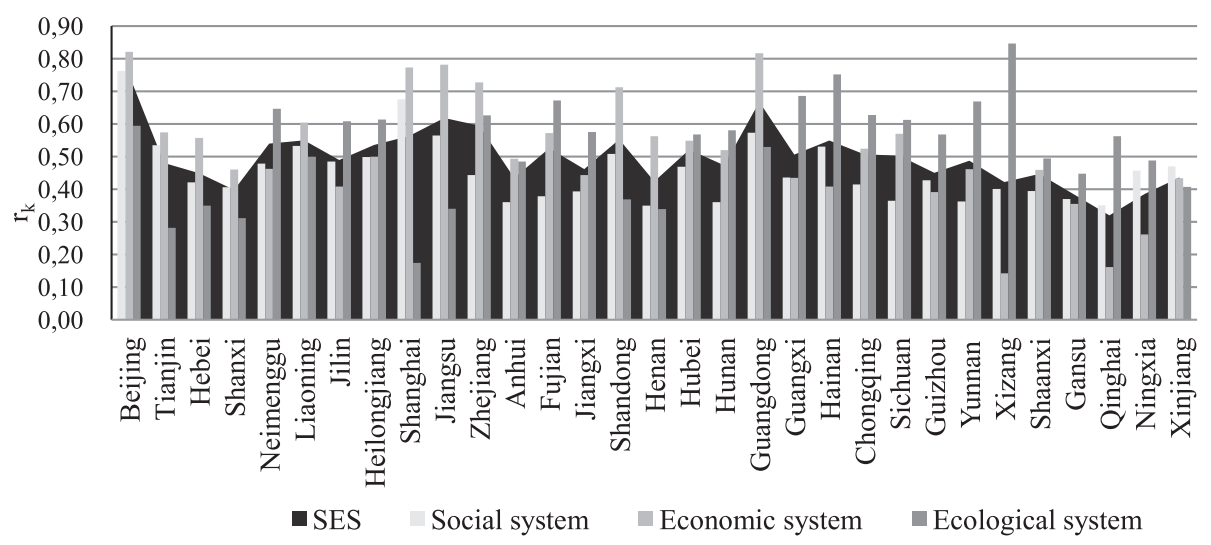

Fig. 3. Vulnerability with respect to the social, economic, and ecological systems, and SES of the provinces in mainland China.

subsystems and the compound system (i.e., the SES). As shown in Fig. 3, the SES vulnerabilities of Beijing, Shanghai, Guangzhou, Jiangsu, and Zhejiang cities were high because rapid urbanization has created numerous social and environmental issues, whereas those of Qinghai, Gansu, Ningxia, Shanxi, and Xizang were relatively low. These results are consistent with the economic system vulnerability index results. In China, there is widespread and intensive focus on economic development; as a result, the economic development in each province has been accelerated while the vulnerability of the compound system has increased.

\section{Analysis of Response Capacity}

According to the results of the response capacity index (Fig. 4), most provinces had considerable response capacity. Because the indicators showed that most provincial cities had considerable response capacities from financial expenditure and government investment to environmental protection. In recent years, China has strongly advocated the policy of sustainable development, especially at the socio-economic level, including the continuous improvement of infrastructure and increased investment in education and health care, as well as at the ecological level by implementing a series of pollution prevention and ecological protection measures such as improving energy consumption structure, intensifying the prevention and the control of industrial pollution, enhancing the governance of river basin water pollution, and projects to turn farmland to forests. The restoration and reconstruction of the ecological environment has proven to be effective.

Xizang and Hainan, which are located in occluded bordering areas with underdeveloped environments, were the only exceptions. The response factors of the subsystems were interrelated; enhanced response capacity in the economic system was a necessary precondition for any enhancement in social and ecological response capacities. There were considerable differences between the response capacities of the social system in different provinces. There was a four-fold difference between Jiangsu and Ningxia. To this effect, the social welfare in less-developed regions should be strengthened to prevent further expansion of the gap between provinces.

\section{Analysis of Social-Ecological Resilience}

There is a significant amount of imbalance between the SES resilience in eastern and western provinces. The

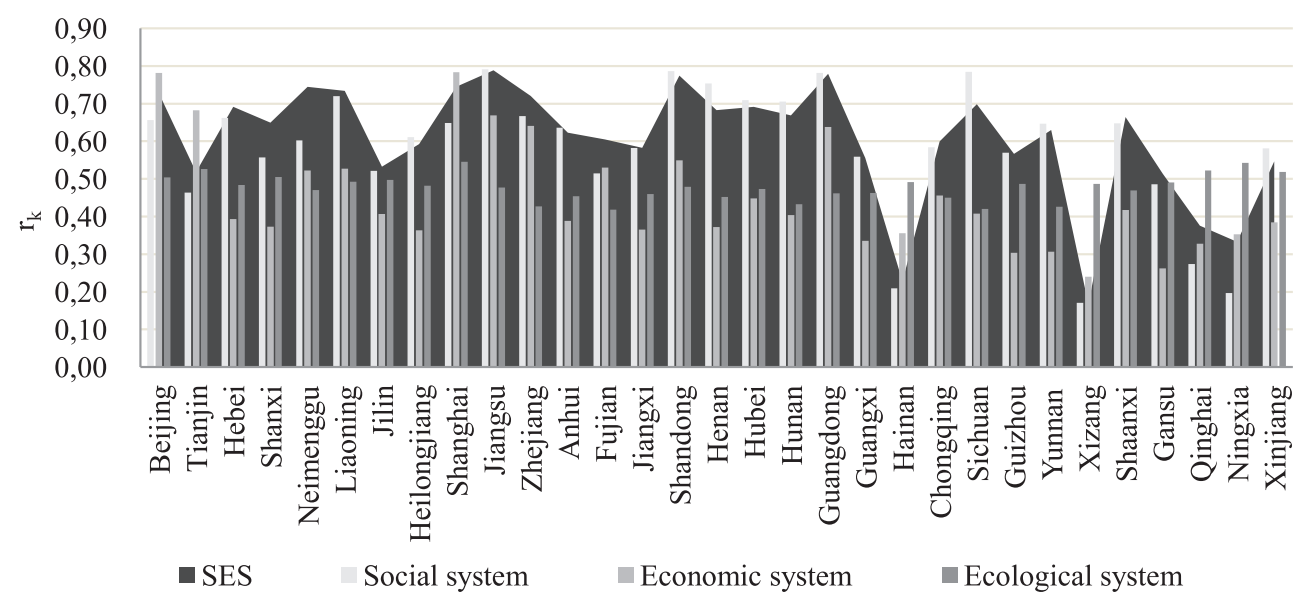

Fig. 4. Response capacity with respect to social system, economic system, ecological system, and SES of provinces in mainland China. 

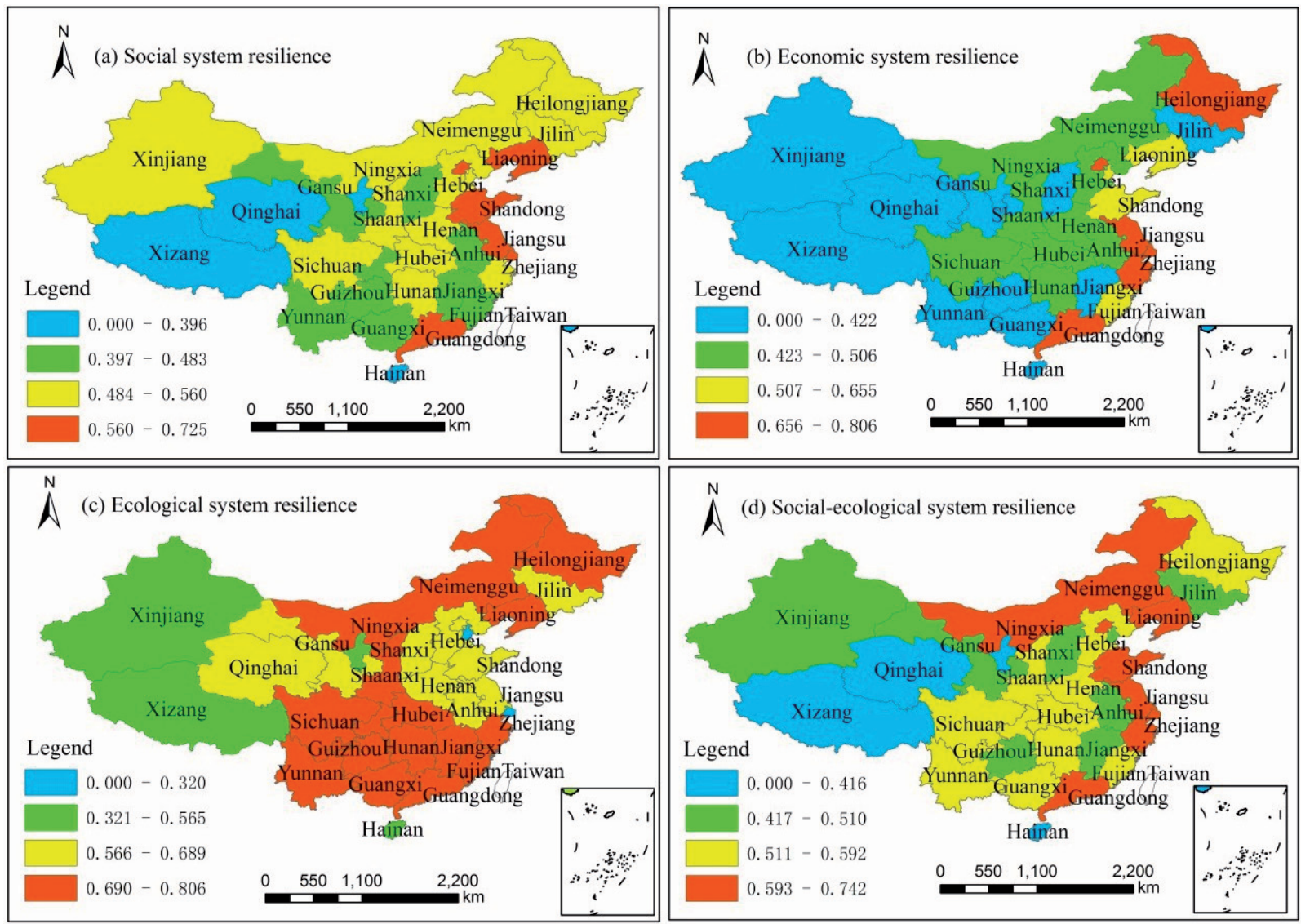

Fig. 5. Resilience with respect to social, economic, and ecological systems, plus SES of provinces in mainland China.

resilience comparison in Fig. 5 shows that relatively few provinces have strong resilience. The resilience levels of the SES of Beijing, Shanghai, Jiangsu, Zhejiang, Guangzhou, Liaoning, and Neimenggu provinces were better than those of Xizang, Qinghai, and Ningxia provinces, as the former have favorable geography and political climates, and have undergone more extensive social and economic development. The provinces with higher resilience are all located along the eastern coast of China, whereas the provinces in the western and central parts of the country had significantly lower resilience. This east-west divide differs substantially from the north-south divide, which is based on geographical and climatic differences more than economic and social differences.

The eastern regions of China are mainly composed of plains, low hills, and fertile lands with suitable temperature and abundant rainfall. However, most of the western regions are composed of mountain plateaus with a large area of desert, so it is difficult for the locals to contact the other regions of the country. Besides, the Reform and Opening-up Policy in China also made it a priority to develop the eastern coastal areas first. Therefore, the eastern regions are significantly better than the western ones in terms of natural ecological background, level of urbanization, GDP, and the rationality of industrial structure. This has determined the spatial differences in social-ecological resilience.
The provinces with higher ecological resilience indices are usually provinces with higher social and economic resilience indices, indicating that the more attention the state pays to ecological protection, the more successful the sustainable development strategy. In regards to the influencing factors of resilience, social welfare, economic development, and infrastructure, construction in western China should be improved. Regions undergoing rapid economic development, such as Beijing and Shanghai, should pay particular attention to ecological problems.

\section{Correlation of Vulnerability, Response Capacity Factors, and SES Resilience}

In a wealthy and resilient system, change has the potential to create development opportunities for novelty and innovation. When a region becomes significantly vulnerable, its resilience may be low and even a minimal change may have disastrous consequences [41]. The core idea of resilience is to prevent any decrease in the constraints on or future opportunities for SES; ideally, resilience creates or enhances learning, the degree of adaptation, and response capacity [10]. Per our analysis, the SES resilience levels of most provinces were moderate, though there were considerable differences between them. The extent of development of the system in regards to any one given factor may have caused a chain of changes in other factors, thereby affecting overall 
Table 4. Pearson correlation between influencing factors and SES resilience.

\begin{tabular}{|c|c|c|c|c|c|c|c|c|c|}
\hline & A1 & $\mathrm{A} 2$ & A3 & A4 & A5 & A6 & A7 & A8 & B1 \\
\hline Pearson correlation & $0.588^{* *}$ & $0.611^{* *}$ & -0.069 & $0.541 * *$ & 0.345 & 0.247 & $0.671^{* *}$ & $0.669^{* *}$ & $0.810^{* *}$ \\
\hline \multirow[t]{2}{*}{$\begin{array}{c}\text { Sig. } \\
\text { (2-tailed) }\end{array}$} & 0.001 & 0.000 & 0.714 & 0.002 & 0.057 & 0.181 & 0.000 & 0.000 & 0.000 \\
\hline & B2 & B3 & B4 & $\mathrm{C} 1$ & $\mathrm{C} 2$ & $\mathrm{C} 3$ & $\mathrm{C} 4$ & $\mathrm{C} 5$ & $\mathrm{C} 6$ \\
\hline Pearson correlation & $0.727 * *$ & 0.117 & $0.738^{* *}$ & $0.726^{* *}$ & 0.331 & -0.089 & $0.660 * *$ & $0.820 * *$ & $0.615^{* *}$ \\
\hline \multirow[t]{2}{*}{$\begin{array}{c}\text { Sig. } \\
\text { (2-tailed) }\end{array}$} & 0.000 & 0.529 & 0.000 & 0.000 & 0.069 & 0.633 & 0.000 & 0.000 & 0.000 \\
\hline & $\mathrm{C} 7$ & $\mathrm{C} 8$ & D1 & D2 & D3 & D4 & E1 & E2 & E3 \\
\hline Pearson correlation & $0.800^{* *}$ & $0.609 * *$ & $0.823^{* *}$ & $0.652 * *$ & $0.593^{* *}$ & 0.344 & -0.111 & 0.302 & -0.287 \\
\hline \multirow[t]{2}{*}{$\begin{array}{c}\text { Sig. } \\
\text { (2-tailed) }\end{array}$} & 0.000 & 0.000 & 0.000 & 0.000 & 0.000 & 0.058 & 0.553 & 0.098 & 0.118 \\
\hline & E4 & E5 & E6 & E7 & E8 & $\mathrm{F} 1$ & $\mathrm{~F} 2$ & F3 & F4 \\
\hline Pearson correlation & 0.161 & $0.365^{*}$ & $0.452 *$ & 0.252 & -0.102 & $0.722 * *$ & 0.159 & 0.236 & 0.080 \\
\hline $\begin{array}{c}\text { Sig. } \\
\text { (2-tailed) }\end{array}$ & 0.387 & 0.043 & 0.011 & 0.172 & 0.586 & 0.000 & 0.393 & 0.200 & 0.670 \\
\hline
\end{tabular}

*Correlation is significant at the 0.05 level (2-tailed).

**Correlation is significant at the 0.01 level (2-tailed).

system resilience. The factors, nature, modes, rates, rules, and other mechanisms that influence resilience merit further investigation, to this effect. Each of the indicators can be standardized based on their respective positive and negative points. We used SPSS 19.0 to analyze the correlation between vulnerability factors, response capacity factors, and SES resilience as reported in Table 4.

The correlations of influencing factors with resilience are mostly weak, so factors with correlations to resilience that are significant at the 0.05 level (2-tailed) were selected. Owing to space constraints, some other factors (e.g., number of traffic accidents, unemployment rate, area of agricultural land, population density) were not included in the analysis.

The vulnerability of the social subsystem includes social stability and infrastructure construction. We found that social stability and total population were significantly negatively correlated with resilience (Fig. 6a). An increase in the total population for economic development can be burdensome enough to society that resilience cannot be recovered quickly within a certain time period. Urbanization and resilience appear to be positively correlated: When urbanization reaches a certain level and stage, it promotes resilience. Fig. 6b) shows that infrastructure construction and resilience are positively correlated. For example, an increase in the length of roads is conducive to the establishment of a convenient transportation network; increasing road length can, to this effect, further improve the investment environment and promote the healthy development of an export-oriented society. Increased green space can improve satisfaction among residents, so green urban construction should be made a priority.
Figs 6(c-d) show that the vulnerability of the economic subsystem is divisible into economic development and revenue. Expenditure can also be split into two parts. All of these factors have a negative correlation with resilience. The total industrial output value reflects the scale of industrial development within a certain time period; an increase in industrial output can elevate resilience in the industrial sector despite fluctuations in the economic environment. For developing countries, investment is the core of the economy and lack of investment reflects a lack of development or additional financial resources. Developing regions require a cycle of investment. The total import and export of goods reflects the openness of a region, which has significant effects on resilience in the mid-low stage of SES establishment but causes diminished marginal utilities. Revenue and expenditure reflect the living standards of residents. Improving them gradually increases system resilience on the whole.

Figs 6(e-f) show that ecological pressure and resilience are negatively related. Increases in sulfur dioxide and nitrogen oxide emissions can lead to a gradual decrease in resilience until the system reaches a state of paralysis. Local economic development exerts considerable pressure on the environment and thus weakens overall SES resilience to a certain extent, despite the different effects on rate and impact properties.

The response capacity of an SES, as discussed above, can be divided into social, economic, and ecological subsystems. In the social subsystem (Fig. 7a), each factor has a low impact on resilience when the response capacity is low. An increase in investment can quickly improve system resilience. When the response capacity is high, the impact of investment increase is relatively flat, and each response capacity remains somewhat limited. 

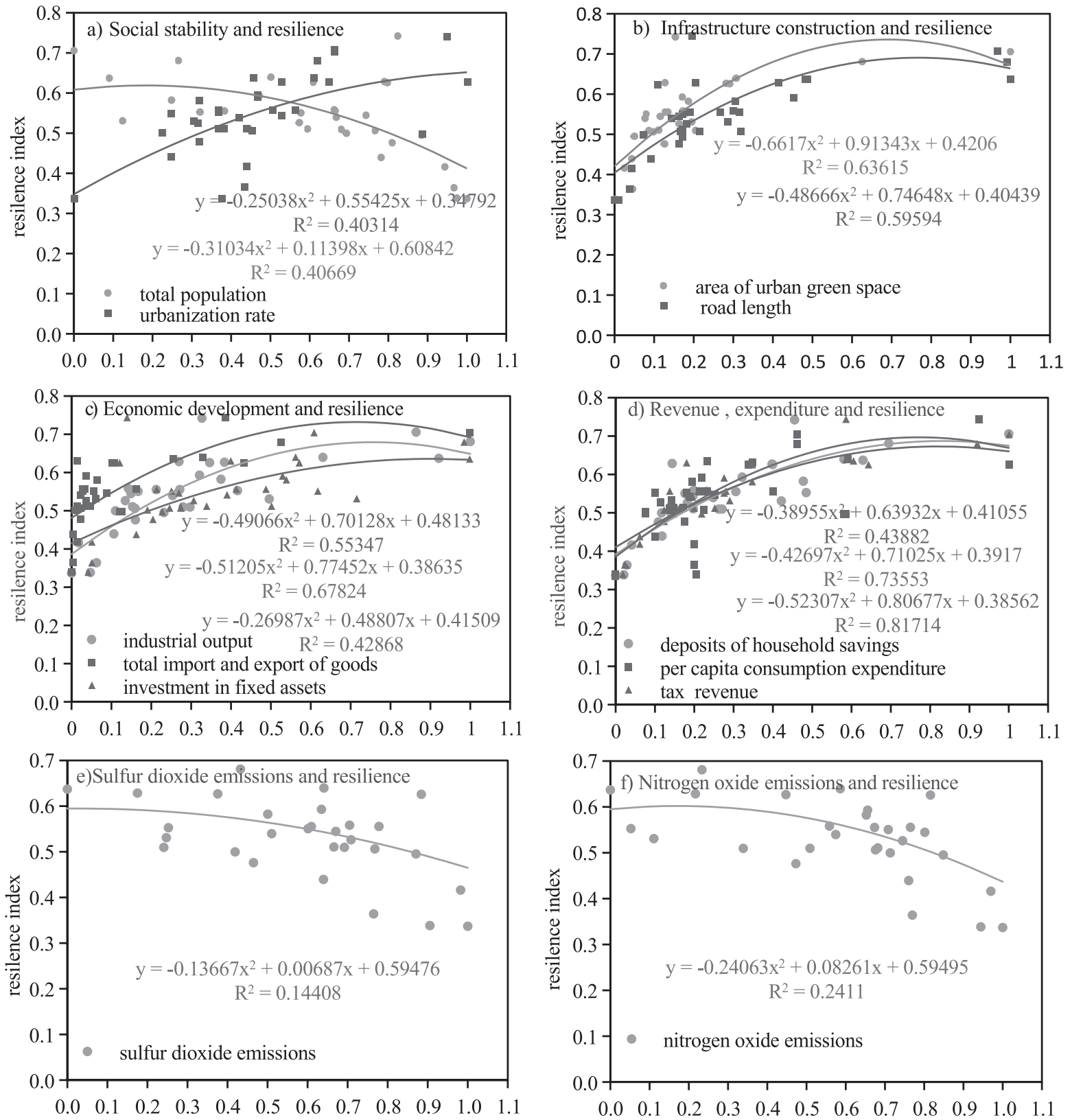

Fig. 6. Correlation of SES vulnerability and resilience in mainland China. a, b): Correlation between social system vulnerability and SES resilience, c, d): Correlation between economic system vulnerability and SES resilience, and e, f): Correlation between ecological system vulnerability and SES resilience.

Different factors are also interrelated. For example, local fiscal expenditure is interrelated with social security, employment, and education expenditures. When government investment is larger, emergency response and SES resilience against risks are enhanced.

We found that in the economic subsystem, the factors were significantly positively correlated with resilience (the trends of their curves are similar) as shown in Fig. 7b). When resilience is still low, improving the income and living standards of residents can improve the SES response capacity and thus contribute to improvemed SES resilience. Once the resilience of the system reaches a certain level, however, the influence of response capacity starts to plateau and resilience slowly trends downward.
Fig. 7c) shows that in the ecological subsystem, the amount of daily sewage treatment and resilience had a significant linear correlation, which suggests that radical ecological action can significantly improve resilience.

\section{Conclusions}

The objective of our study was to assess, objectively and quantitatively, the resilience of SES in mainland China. We established a model for the distribution of resilience by using information entropy and SPA, and found that the said model can be effectively applied to the analysis of urban social, economic, and ecological 

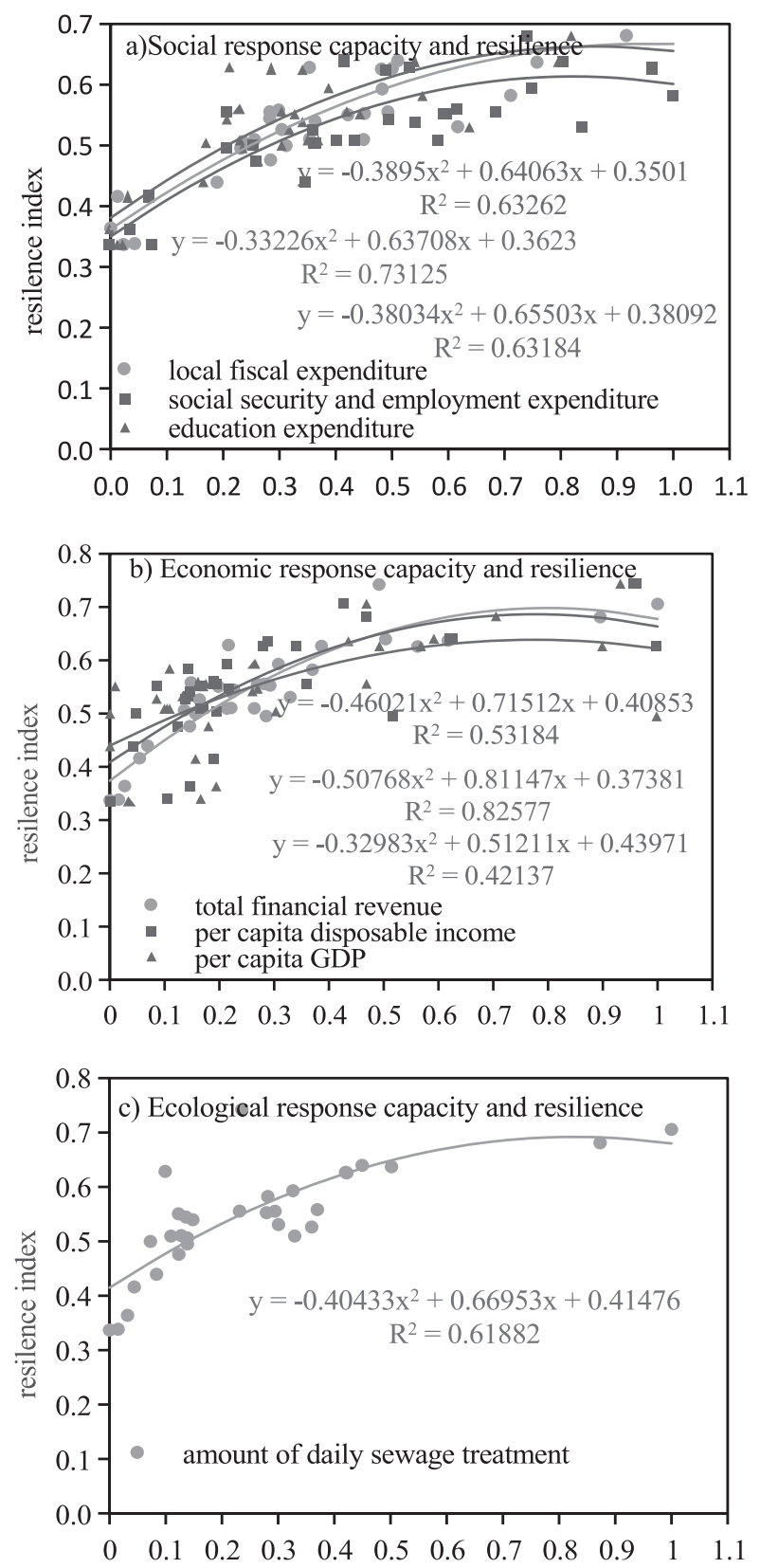

Fig. 7. Correlation of SES response capacity and resilience in mainland China.

subsystems in transition. Generally, there is a quadratic linear relationship between any one driving factor and resilience. The acting direction and rate of each driving factor were uncertain, confirming the applicability of SPA and regression methods.

In this study, the vulnerabilities of different provinces varied across China, but with a strong response capacity, provinces were shown to be able to adapt economically and socially. Only seven provinces exhibited strong resilience. In this complex situation, regions that have yet to develop economically should strengthen economic and policy investments to close in on economically advantaged provinces, while economically developed areas should reduce the negative impact of resource development on the environment.
Generally, improvement of SES resilience is the result of joint actions in several subsystems. For example, rapid economic development introduces a certain degree of pressure. In different stages of resilience, the driving factors exert different actions and effects on the system. In different stages of resilience, the driving factors exert different actions and effects on the system. Our results suggest that China would do well to increase social investment, encourage conservation and eco-friendly use of resources, and effectively improve the emergency response capacity to enhance SES resilience at the national level.

The indicators of driving factors and models of SES merit further improvement. Future studies should be designed around more comprehensive evaluation systems, sequencing driving factors according to their importance, and performing coupled analyses of sustainability and resilience.

\section{Acknowledgements}

This research was supported by the National R\&D Program of China (2016YFC0502803).

\section{References}

1. HOLLING C.S. Resilience and stability of ecological systems. Annual Review of Ecology and Systematics. 4 (1), $1,1973$.

2. CAPON S.J., LYNCH A.J., BOND N., CHESSMAN B.C., DAVIS J., DAVIDSON N., FINLAYSON M., GELL P.A., HOHNBERG D., HUMPHREY C., KINGSFORD R.T., NIELSEN D., THOMSON J.R., WARD K., NALLY M.R. Regime shifts, thresholds and multiple stable states in freshwater ecosystems; a critical appraisal of the evidence. The Science of the Total Environment. 534 (15), 122, 2015.

3. LI Y., LI Y., WU W. Threshold and resilience management of coupled urbanization and water environmental system in the rapidly changing coastal region. Environmental Pollution. 208, 87, 2015.

4. MAY R.M. Thresholds and breakpoints in ecosystems with a multiplicity of stable states. Nature. 269 (5628), 471, 1977.

5. WILLIS K.J., BAILEY R.M., BHAGWAT S.A., BIRKS H.J. Biodiversity baselines, thresholds and resilience: testing predictions and assumptions using palaeoecological data. Trends in Ecology \& Evolution. 25 (10), 583, 2010.

6. ZAUCHA J., CONIDES A., KLAOUDATOS D., NORÉN $\mathrm{K}$. Can the ecosystem services concept help in enhancing the resilience of land-sea social-ecological systems? Ocean \& Coastal Management. 124, 33, 2016.

7. COTE M., NIGHTINGALE A.J. Resilience thinking meets social theory: situating social change in socio-ecological systems (SES) research. Progress in Human Geography. 36 (4), 475, 2012.

8. ZHOU H., WAN J., JIA H. Resilience to natural hazards: a geographic perspective. Natural Hazards. 53 (1), 21, 2010.

9. RUIZ-BALLESTEROS E. Social-ecological resilience and community-based tourism. Tourism Management. 32 (3), $655,2011$. 
10. KELLY C., FERRARA A., WILSON G.A., RIPULLONE F., NOLEOLÈ A., HARMER N., SALVATI L. Community resilience and land degradation in forest and shrubland socio-ecological systems: Evidence from Gorgoglione, Basilicata, Italy. Land Use Policy. 46, 11, 2015.

11. LI, Y. SHI Y., QURESHI S., BRUNS A., ZHU X. Applying the concept of spatial resilience to socio-ecological systems in the urban wetland interface. Ecological Indicators. 42, 135,2014

12. MAHBOUBI P., PARKES M., STEPHEN C., CHAN H.M. Using expert informed GIS to locate important marine social-ecological hotspots. Journal of Environmental Management. 160, 342, 2015.

13. KOTEE I., REYERS B. Piloting a social-ecological index for measuring flood resilience: A composite index approach. Ecological Indicators. 60, 45, 2016.

14. MÜLLER F., BERGMANN M., DANNOWSKI R., DIPPNER J.W., GNAUCK A., HAASE P., JOCHIMSEN M.C., KASPRZAK P., KRÖNCKE I., KÜMMERLIN R., KÜSTER M., LISCHEID G., MEESENBURG H., MERZ C., MILLAT G., MÜLLER J., PADISÁK J., SCHIMMING C.G., SCHUBERT H., SCHULT M., SELMECZY G., SHATWELL T., STOLL S., SCHWABE M., SOLTWEDEL T., STRAILE D., THEUERKAUF M. Assessing resilience in long-term ecological data sets. Ecological Indicators. 65, 10, 2016.

15. WALKER B., HOLLING C.S., CARPENTER S.R., KINZIG A. Resilience, adaptability and transformability in social-ecological systems. Ecology and Society. 9 (2), 5, 2004.

16. OLSSON P., FOLKE C., BERKES F. Adaptive comanagement for building resilience in social-ecological systems. Environmental management. 34 (1), 75, 2004.

17. ADGER W.N., HUGHES T.P., FOLKE C., CARPENTER S.R., ROCKSTRÖM J. Social-ecological resilience to coastal disasters. Science. 309 (5737), 1036, 2005.

18. O'BRIEN K., SYGNA L., HAUGEN J.E. Vulnerable or resilient? A multi-scale assessment of climate impacts and vulnerability in Norway. Climatic Change. 64 (1), 193, 2004

19. HASHEMI S.M., BAGHERI A., MARSHALL N. Toward sustainable adaptation to future climate change: insights from vulnerability and resilience approaches analyzing agrarian system of Iran. Environment, Development and Sustainability. 19 (1), 1, 2017.

20. PERZ S.G., MUÑOZ-CARPENA R., KIKER G., HOLT R.D. Evaluating ecological resilience with global sensitivity and uncertainty analysis. Ecological Modelling. 263, 174, 2013.

21. CUTTER S.L., BARNES L., BERRY M., BURTON C., EVANS E., TATE E. A place-based model for understanding community resilience to natural disasters. Global Environmental Change. 18 (4), 598, 2008.

22. ZAUCHA J., CONIDES A., KLAOUDATOS D., NORÉN $\mathrm{K}$. Can the ecosystem services concept help in enhancing the resilience of land-sea social-ecological systems? Ocean \& Coastal Management. 124, 33, 2016.

23. SU M.R., YANG Z.F., CHEN B. Set pair analysis for urban ecosystem health assessment. Communications in Nonlinear Science and Numerical Simulation. 14 (4), 1773, 2009.

24. ZOU Q., ZHOU J.Z., ZHOU C., SONG L.X., GUO J. Comprehensive flood risk assessment based on set pair analysis-variable fuzzy sets model and fuzzy AHP. Stochastic Environmental Research and Risk Assessment. 27 (2), 525, 2013.
25. CUTTER S.L., BARNES L., BERRY M., BURTON C., EVANS E., TATE E., WEBB J. A place-based model for understanding community resilience to natural disasters. Global Environmental Change. 18(4), 598, 2008.

26. MARU Y.T., STAFFORD S.M., SPARROW A., PINHO P.F., DUBE O.P. A linked vulnerability and resilience framework for adaptation pathways in remote disadvantaged communities. Global Environmental Change. 28, 337, 2014.

27. WANG L., SHA J., AN Q. Evaluation of environmental protection levels using grey relational analysis. Polish Journal of Environmental Studies. 23 (5), 1753, 2014.

28. SUN L., NI J., BORTHWICK A.G. Rapid assessment of sustainability in Mainland China. Journal of Environmental Management. 91 (4), 1021, 2010.

29. BANOS-GONZÁLEZ I., MARTÍNEZ-FERNÁNDEZ J., ESTEVE-SELMA M.Á. Dynamic integration of sustainability indicators in insular socio-ecological systems. Ecological Modelling. 306, 130, 2015.

30. LACITIGNOLA D., PETROSILlO I., CATALDI M., ZURLINI G. Modelling socio-ecological tourism-based systems for sustainability. Ecological Modelling. 206 (1), 191, 2007.

31. HAN B., LIU H., WANG R. Urban ecological security assessment for cities in the Beijing-Tianjin-Hebei metropolitan region based on fuzzy and entropy methods. Ecological Modelling. 318, 217, 2015.

32. HAN B., WANG R., TAO Y., GAO H. Urban population agglomeration in view of complex ecological niche: A case study on Chinese prefecture cities. Ecological Indicators. 47, 128, 2014.

33. LI F., LIU X., HU D., WANG R., YANG W., LI D., ZHAO $D$. Measurement indicators and an evaluation approach for assessing urban sustainable development: A case study for China's Jining City. Landscape and Urban Planning. 90 (3), 134, 2009.

34. ZHAO K.Q. Set pair and set pair analysis-a new concept and systematic analysis method. In: Proceedings of the National Conference on System Theory and Regional Planning. 87, 1989 [In Chinese].

35. CHUNYING Z., RUITAO L., LU L., JING W. Set Pair Community Mining and Situation Analysis Based on Web Social Network. Procedia Engineering. 15, 3456, 2011.

36. HU J., YANG L. Dynamic stochastic multi-criteria decision making method based on cumulative prospect theory and set pair analysis. Systems Engineering Procedia. 1, 432, 2011.

37. WEI C., DAI X., YE S., GUO Z., WU J. Prediction analysis model of integrated carrying capacity using set pair analysis. Ocean \& Coastal Management. 120, 39, 2016.

38. YUE W., CAIY., RONG Q., LIC., REN L. A hybrid life-cycle and fuzzy-set-pair analyses approach for comprehensively evaluating impacts of industrial wastewater under uncertainty. Journal of Cleaner Production. 80, 57, 2014.

39. SU M.R., YANG Z.F., CHEN B., ULGIATI S. Urban ecosystem health assessment based on emergy and set pair analysis - A comparative study of typical Chinese cities. Ecological Modelling. 220 (18), 2341, 2009.

40. ZHANG Y., YANG Z., LI W. Analyses of urban ecosystem based on information entropy. Ecological Modelling. 197 (1), $1,2006$.

41. TURNER B.L. Vulnerability and resilience: Coalescing or paralleling approaches for sustainability science? Global Environmental Change. 20 (4), 570, 2010. 